https://doi.org/10.15407/ujpe66.3.221

V.I. GRYTSAY

Bogolyubov Institute for Theoretical Physics, Nat. Acad. of Sci. of Ukraine

(14b, Metrolohichna Str., Kyiv 03680,Ukraine; e-mail: vgrytsay@bitp.kiev.ua)

\title{
SPECTRAL ANALYSIS AND INVARIANT MEASURE IN STUDIES OF THE DYNAMICS OF THE HEMOSTASIS OF A BLOOD VESSEL
}

\begin{abstract}
A mathematical model of atherosclerosis of a blood vessel is advanced with regard for the entry of low-density lipoproteins (LDLs) into blood. For the first time, the influence of cytokines on the inflammation of a blood vessel at the formation of atherosclerotic plaques is taken into account. With the help of the expansion in a Fourier series and the calculation of an invariant measure, the scenario of the appearance of strange attractors depending on a change in the parameter of the dissipation of cholesterol is studied. The conclusion is made about the interconnection of the dynamics of the metabolic process in a blood vascular system and its physical state.
\end{abstract}

Ke ywords: hemostasis, self-organization, strange attractor, Fourier series, invariant measure, low-density lipoproteins, cytokines.

\section{Introduction}

The blood composition stability has a particular meaning for the vital activity of organism. There exist two counteracting systems in blood vessels: namely, the fibrillation and liquefaction ones which are in the functional equilibrium, by preventing the fibrillation of blood and forming the hemostasis of a blood vessel [1-4]. The regulators of the fibrillation of blood are thromboxanes and prostacyclins. A number of researchers modeled the given process and other analogous ones, trying to get the comprehensive knowledge about them [5-15]. The author developed a mathematical model of the prostacyclin-thromboxane system of a blood vessel, determined the conditions for the self-organization of the system and for the appearance of stationary stable autoperiodic oscillations, and studied the conditions for the development of hemophilia and thrombosis [16-21]. In the frame of this approach, a mathematical model of blood vessel with regard for the presence of low-density lipopro-

(c) V.I. GRYTSAY, 2021

ISSN 2071-0194. Ukr. J. Phys. 2021. Vol. 66, No. 3 teins (LDLs) such as "poor cholesterol" in blood and the formation of atherosclerotic plaques in blood vessels was constructed in $[22,23]$, and the influence of LDLs on the self-organization of the hemostasis of a blood vessel and the formation of dynamical chaotic modes in the system was studied. The interval of a level of the dissipation of cholesterol from blood, where chaotic autooscillations can arise, was determined. The phase-parametric diagram of autooscillatory modes depending on the dissipation of cholesterol from blood was constructed. The scenario of bifurcations with a period doubling until the aperiodic modes of strange attractors arise due to the intermittence was described, and the strange attractors appeared as a result of the formation of a mixing funnel were constructed. The complete spectra of Lyapunov exponents for various modes were calculated. For strange attractors, the Kolmogorov-Sinai (KS) entropy, "foresight horizons," and Lyapunov's dimensions of the fractality of attractors were determined. It was shown that the cause for changes in the metabolic process of hemostasis of a blood vessel can 


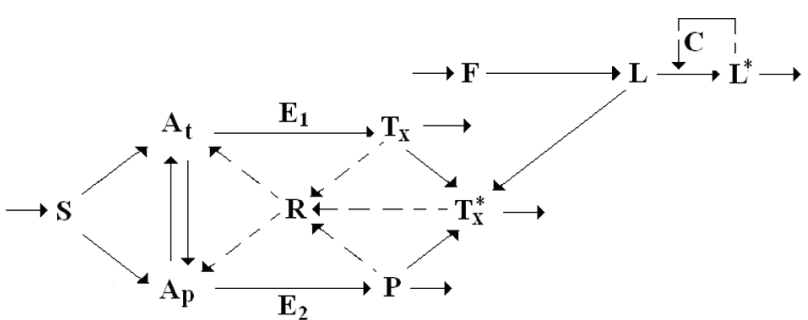

Fig. 1. General kinetic scheme of hemostasis of a blood vessel

be the insufficient level of the dissipation of cholesterol from blood. The study of the dependence of autooscillatory modes on the fat concentration in blood was carried out, and the chaotic modes of strange attractors were found. Such modes lead to the disbalance between the amount of "poor cholesterol" deposited in a blood vessel and its removal from the system. This provokes the formation of plaques in arteries. It was shown that LDLs affect the binding of thrombocytes and are deposited in the walls of blood vessels. This causes the autocatalysis of cholesterol in blood and an increase in its level. The mathematical study of the determined modes was carried out.

In the present work, we continue the study of this system with regard for the presence of "poor cholesterol" in blood. In more details, we will consider the physical process of autocatalysis at the formation of atherosclerotic plaques. For the first time, the mechanism of the given process is modeled. According to author's hypothesis, it will be proved here that the autocatalysis occurs due to the action of cytokines, and their role in the given process will be estimated. Within the new model, we will study the influence of the dissipation of cholesterol on the selforganization of the metabolic process and on the appearance of a dynamical chaos in the system. With the help of spectral analysis, by constructing the projections of a phase portrait and its invariant measure, we will study the formation of a strange attractor.

\section{Mathematical Model}

Here, the overall scheme of the metabolic process of hemostasis of a blood vessel [22, 23] is generalized by including the influence of cytokines on the formation of atherosclerotic plaques (see Fig. 1). The model includes a system of 12 differential equations (1)-(12) describing changes in the concentrations of components. In its construction, we used the law of mass action and the enzyme catalysis kinetics. The equations are written with regard for the balance of masses of intermediate products of the reactions between separate stages of the metabolic process. We have

$$
\begin{aligned}
& \frac{d A_{t}}{d t}=\frac{k_{5} S}{\left(1+S+R^{2}\right)\left(1+k_{6} T_{x}\right)}- \\
& -\frac{k_{7} A_{t} E_{1}}{\left(1+A_{t}+k_{1} T_{x}\right)\left(1+E_{1}\right)}+k_{p} A_{p}-k_{t} A_{t}-\alpha_{1} A_{t}, \quad(1) \\
& \frac{d T_{x}}{d t}=\frac{k_{7} A_{t} E_{1}}{\left(1+A_{t}+k_{1} T_{x}\right)\left(1+E_{1}\right)}-\frac{k_{8} T_{x}^{4}}{\left(k_{9}+T_{x}^{4}\right)}-\alpha_{2} T_{x},
\end{aligned}
$$

$\frac{d A_{p}}{d t}=\frac{k_{2} S R^{2}}{\left(1+S+k_{3} A_{p}\right)\left(k_{4}+R^{2}\right)}-$

$-\frac{k_{10} A_{p} E_{2}}{\left(1+A_{p}\right)\left(1+E_{2}\right)}+k_{t} A_{t}-k_{p} A_{p}-\alpha_{3} A_{p}$,

$\frac{d P}{d t}=\frac{k_{10} A_{p} E_{2}}{\left(1+A_{p}\right)\left(1+E_{2}\right)}-\frac{k_{11} T_{x}^{*} P^{4}}{\left(1+T_{x}^{*}\right)\left(k_{12}+P^{4}\right)}-\alpha_{4} P$,

$\frac{d E_{1}}{d t}=\frac{k_{13} A_{T}}{\left(1+A_{T}\right)\left(1+R^{4}\right)}-$

$-\frac{k_{7} A_{t} E_{1}}{\left(1+A_{t}+k_{1} T_{x}\right)\left(1+E_{1}\right)}-\alpha_{5} E_{1}$,

$\frac{d E_{2}}{d t}=\frac{k_{15} A_{p} T_{x}^{* 4}}{\left(k_{16}+A_{p}\right)\left(k_{17}+T_{x}^{* 4}\right)}-$

$-\frac{k_{10} A_{p} E_{2}}{\left(1+A_{p}\right)\left(1+E_{2}\right)}-\alpha_{6} E_{2}$,

$\frac{d R}{d t}=k_{18} \frac{k_{19}+T_{x}^{* 4}}{k_{20}+\left(T_{x}^{*}+k_{21} R\right)^{4}}-\alpha_{7} R$,

$\frac{d T_{x}^{*}}{d t}=k_{8} \frac{L+T_{x}^{4}}{k_{9}+L+T_{x}^{4}}-\frac{k_{11} T_{x}^{*} P^{4}}{\left(1+T_{x}^{*}\right)\left(k_{12}+P^{4}\right)}-\alpha_{8} T_{x}^{*}$.

$\frac{d F}{d t}=F_{0}-l \frac{C}{1+C} \frac{F}{1+F+L}$

$\frac{d L}{d t}=k \frac{C}{1+C} \frac{F}{1+F+L}-\mu \frac{L L^{*}}{1+L+L^{*}}$,

$\frac{d L^{*}}{d t}=\mu_{1} \frac{L L^{*}}{1+L+L^{*}}-\mu_{0} L^{*}$,

$\frac{d C}{d t}=C_{0} L^{*} \frac{F}{1+F} \frac{N}{N+L}-\alpha_{9} C$.

We consider that the principal regulators of the hemostasis and the formation of thrombi are endotheliocytes of a blood vessel.

ISSN 2071-0194. Ukr. J. Phys. 2021. Vol. 66, No. 3 
By Fig. 1, the input substance for the thrombosisantithrombosis system is essential arachidonic fat acid $S$ which enters blood from intestinal tract. Under the action of phospholipases, the acid is accumulated in thrombocytes $A_{p}(3)$ and endotheliocytes $A_{t}$ (1) of a blood vessel. Then it is transformed by prostaglandin- $H$-synthetase of thrombocytes $E_{1}$ (5) and prostaglandin- $H$-synthetase of prostacyclins $E_{2}$ (6) with the formation of, respectively, thromboxanes $T_{x}(2)$ and prostacyclins $P(4)$. These prostaglandins are antagonists to each other. By interacting, they form the dynamical biochemical equilibrium in the fibrillation of blood. But if the conditions of aggregation of thrombocytes are satisfied, then the sequence of metabolic processes with their interaction starts. The given reactions transform the input inflammatory substances that are formed in atherosclerotic plaques at the aggregation of thrombocytes $T_{x}^{*}(8)$. When the plaques are destroyed, the inflammatory substances interact with blood and form a thrombus, which leads to infarct or insult.

Depending on the formed levels of $P, T_{x}$, and $T_{x}^{*}$ (Fig. 1), the amount of the regulating component, cytoplasmatic guanylate cyclase $R(7)$, varies. It inhibits the aggregation of thrombocytes. This occurs under the action of the negative feedback affecting the level of activity of phospholipases of endotheliocytes $A_{t}$ and thrombocytes $A_{p}$. Moreover, these reactions regulate the entrance of arachidonic acid into endotheliocytes and thrombocytes and the amounts of prostacyclin (3) and thromboxane (1). A change in $R$ causes the formation of different modes affecting the development of the hemostasis of a blood vessel.

Another input substance of the system is fat molecules $F(9)$. They are transported by blood along arteries and influence the level of "poor cholesterol," i.e., LDLs. Its level is denoted by the variable $L$ (10). It is formed in liver and small intestine.

From blood, the excessive LDL particles enter the arterial wall of a blood vessel, are chemically changed, and are accumulated there. Modified LDLs stimulate endotheliocytes to the activation of adhesion receptors which bind to monocytes of blood and lure them into intima. In addition, monocytes produce numerous mediators of inflammation, in particular, cytokines (transmitters of signals between cells of the immune system) C (12), and cover their surface by waste receptors that help them to absorb modified LDLs.
In intima, monocytes ripen and become active macrophages. Macrophages absorb LDLs, by filling themselves with fat and forming a foam of oxidized lipoproteins. The fat strips which are the early manifestation of atherosclerotic plaques $L^{*}(11)$ are formed.

Cytokines and inflammatory molecules formed in foamy cells of macrophages favor the further growth of plaques.

In the metabolic process, the positive feedback of the growth of plaques $L^{*}$ and the concentration of inflammatory substances $T_{x}^{*}$ is formed, because cytokines $\mathrm{C}$ activate (10)-(12) the process of absorption of LDLs (10), (11) by macrophages.

The accumulation of cholesterol in arteries and the growth of plaques cause thrombophilia, the narrowing of a blood-carrying artery, and stenosis.

Depending on the dissipation of LDLs in the metabolic process of hemostasis of a blood vessel, the autooscillatory and chaotic modes can appear instead of stationary ones.

The model contains the following parameters:

$k=4 ; \quad k_{1}=3 ; \quad k_{2}=1 ; \quad k_{3}=5 ; \quad k_{4}=10 ;$

$k_{5}=2.1 ; \quad k_{6}=5 ; \quad k_{7}=2 ; \quad k_{8}=1.5 ; \quad k_{9}=5 ;$

$k_{10}=0.75 ; \quad k_{11}=0.3 ; \quad k_{12}=15 ; \quad k_{13}=0.75 ;$

$k_{15}=1 ; \quad k_{16}=0.5 ; \quad k_{17}=5 ; \quad k_{18}=5 ;$

$k_{19}=0.02 ; \quad k_{20}=25 ; \quad k_{21}=0.5 ; \quad k_{p}=0.1 ;$

$k_{t}=0.1 ; \quad S=2 ; \quad \alpha_{1}=0.01 ; \quad \alpha_{2}=0.01 ;$

$\alpha_{3}=0.01 ; \quad \alpha_{4}=0.173 ; \quad \alpha_{5}=0.05 ; \quad \alpha_{6}=0.07$;

$\alpha_{7}=0.2 ; \quad \alpha_{8}=0.0021 ; \quad \alpha_{9}=0.2 ; \quad F_{0}=0.01 ;$

$l=2 ; \quad \mu=4 ; \quad \mu_{0}=0.42 ; \quad \mu_{1}=2.3 ;$

$C_{0}=11 ; \quad N=0.05$.

The study of solutions of the mathematical model (1)-(12) was executed with the help of the application of the theory of nonlinear differential equations [24, 25 and the developed methods of mathematical modeling of biochemical systems [26-59]. The numerical solution was carried out by the Runge-Kutta-Merson method with an accuracy of $10^{-8}$.

\section{Results of Studies}

In the present work, we continue the investigation of the autooscillatory modes in the metabolic process of 


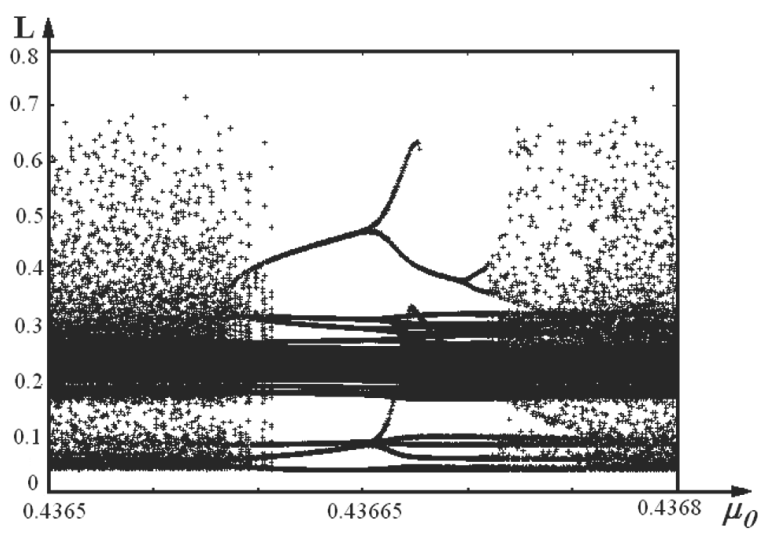

$a$

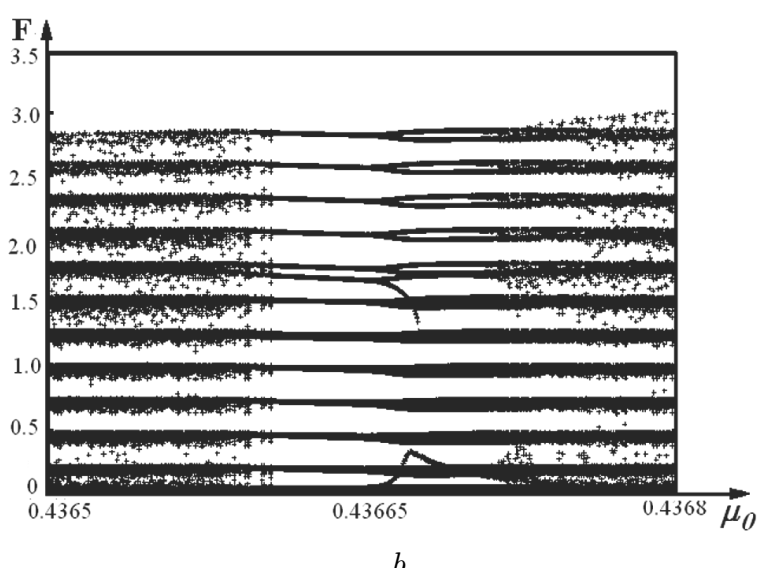

$b$

Fig. 2. Phase-parametric diagrams of the variables $L(t)$ and $F(t)$ versus the parameter of the dissipation of cholesterol from a blood vessel $\mu_{0}$
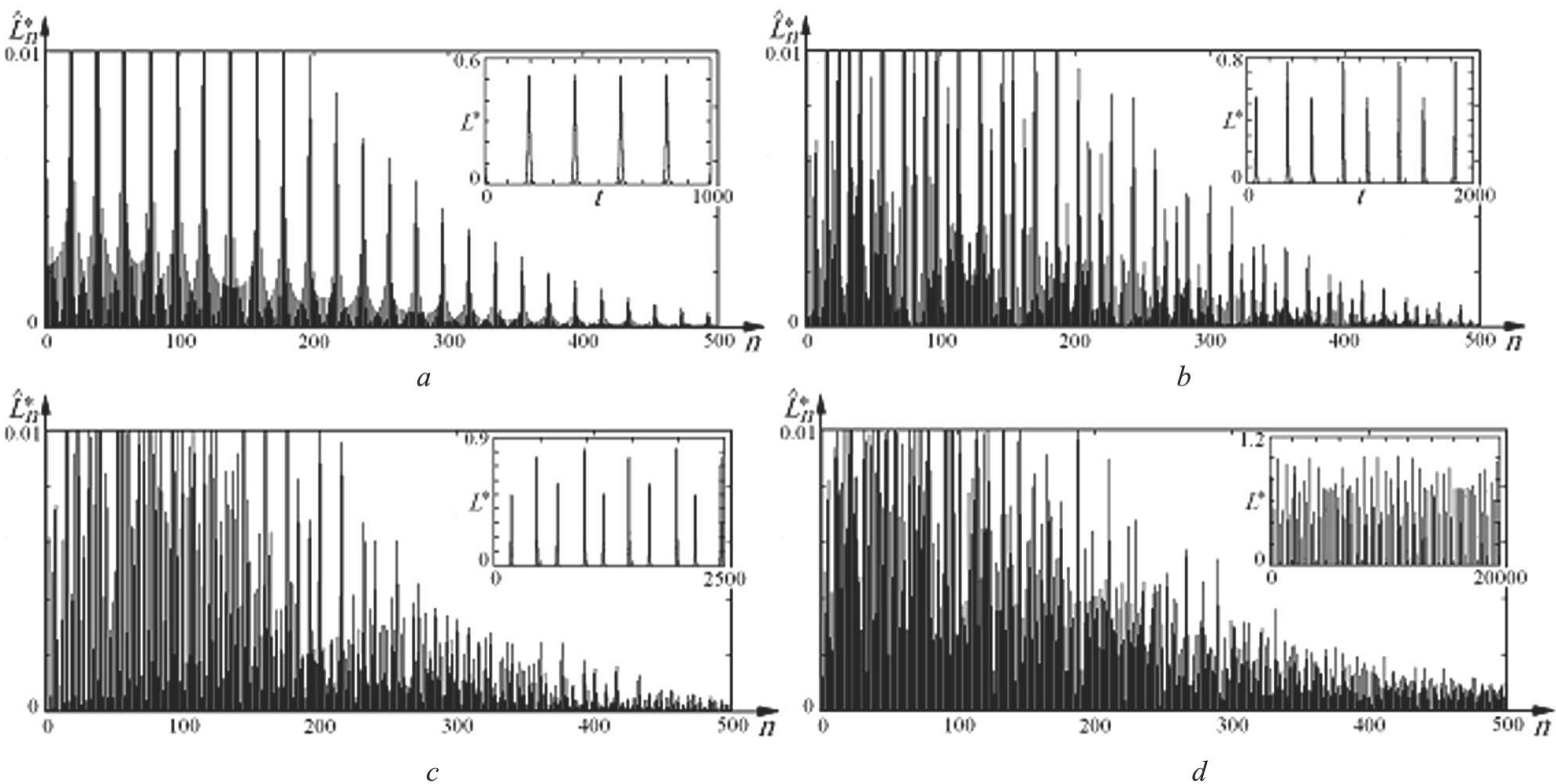

Fig. 3. Distribution of Fourier harmonics in the modes of successive period doubling and dynamical chaos of the metabolic process in a blood vessel: regular attractor $2^{0}\left(\mu_{0}=0.43\right)[22](a)$; regular attractor $1 \times 2^{1}\left(\mu_{0}=0.435\right)[22](b)$; regular attractor $1 \times 2^{2}\left(\mu_{0}=0.43555\right)[22](c)$; strange attractor $1 \times 2^{x}\left(\mu_{0}=0.437\right)[22](d)$

hemostasis of a blood vessel. The obtained dynamical modes $[22,23]$ indicate the dependence of the dynamics of the process on a change in the level of cholesterol in blood.

We now consider the influence of cholesterol plaques on the appearance of a dynamical chaos in the given process.

The calculations showed that, in the interval $\eta_{0} \in$ $\in(0.43,0.438)$, the transition from the stable autoperiodic modes to chaotic ones occurs in the system.
In Fig. 2, $a, b$, we present the phase-parametric diagrams of the system for the variables $L(t)$ and $F(t)$ as functions of the parameter $\mu_{0}$ corresponding to the dissipation of cholesterol from a blood vessel.

In the construction of the phase-parametric diagrams, we apply the method of cutting [22].

We now study the scenario of the transition from the autooscillatory modes to a dynamical chaos with the help of spectral analysis. In Fig. 3, we give the spectra of the expansion of the kinetic curve $L^{*}$ in a 

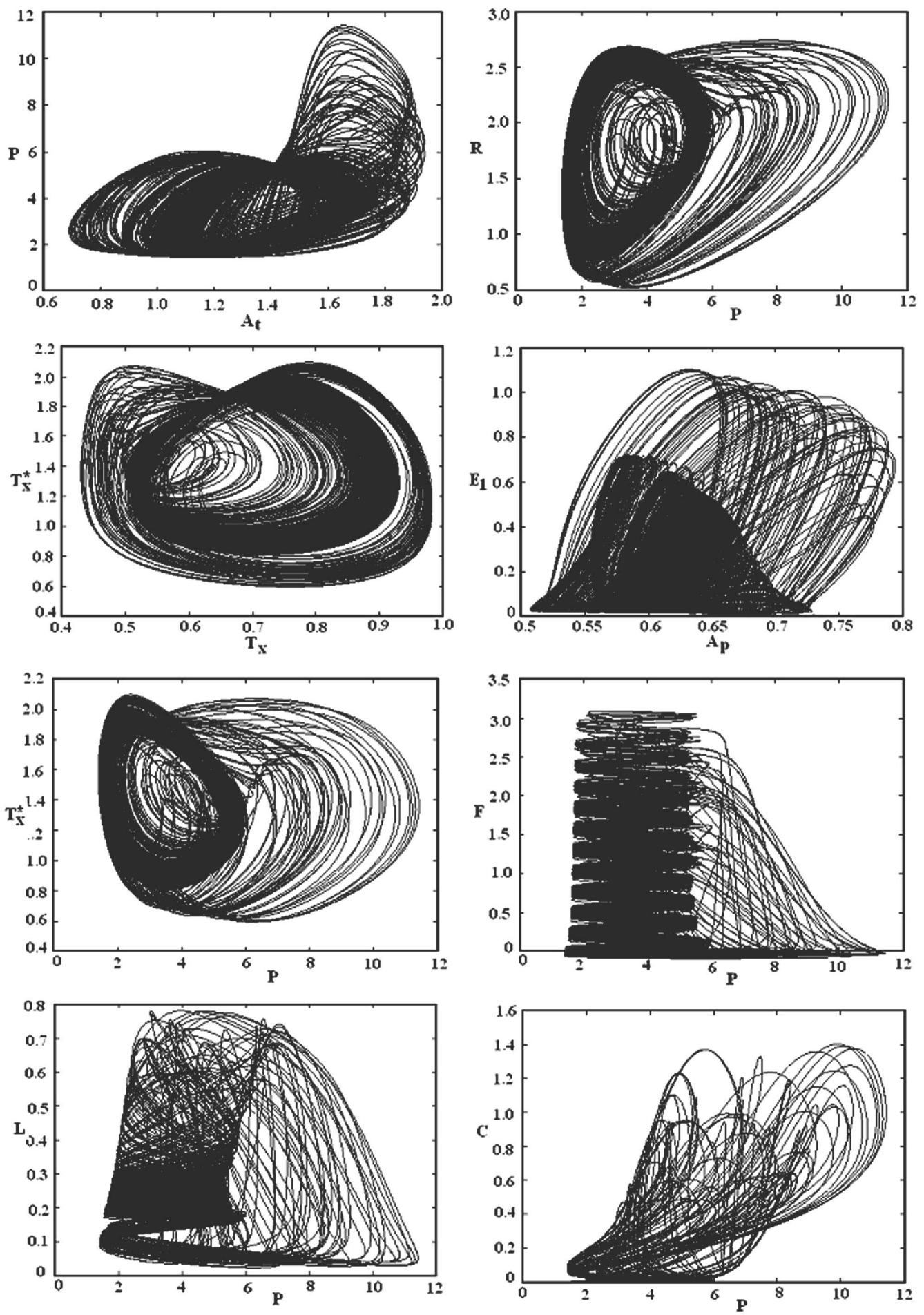

Fig. 4. Projections of the phase portrait of a strange attractor $1 \times 2^{x}$ at $\mu_{0}=0.437$ : in the plane $\left(A_{t}\right.$, $P)(a)$; in the plane $(P, R)(b)$; in the plane $\left(T_{x}, T_{x}^{*}\right)(c)$; in the plane $\left(A_{P}, E_{1}\right)(d)$; in the plane $(P$, $\left.T_{x}^{*}\right)(e)$; in the plane $(P, F)(f)$; in the plane $(P, L)(g)$; in the plane $(P, C)(h)$ 

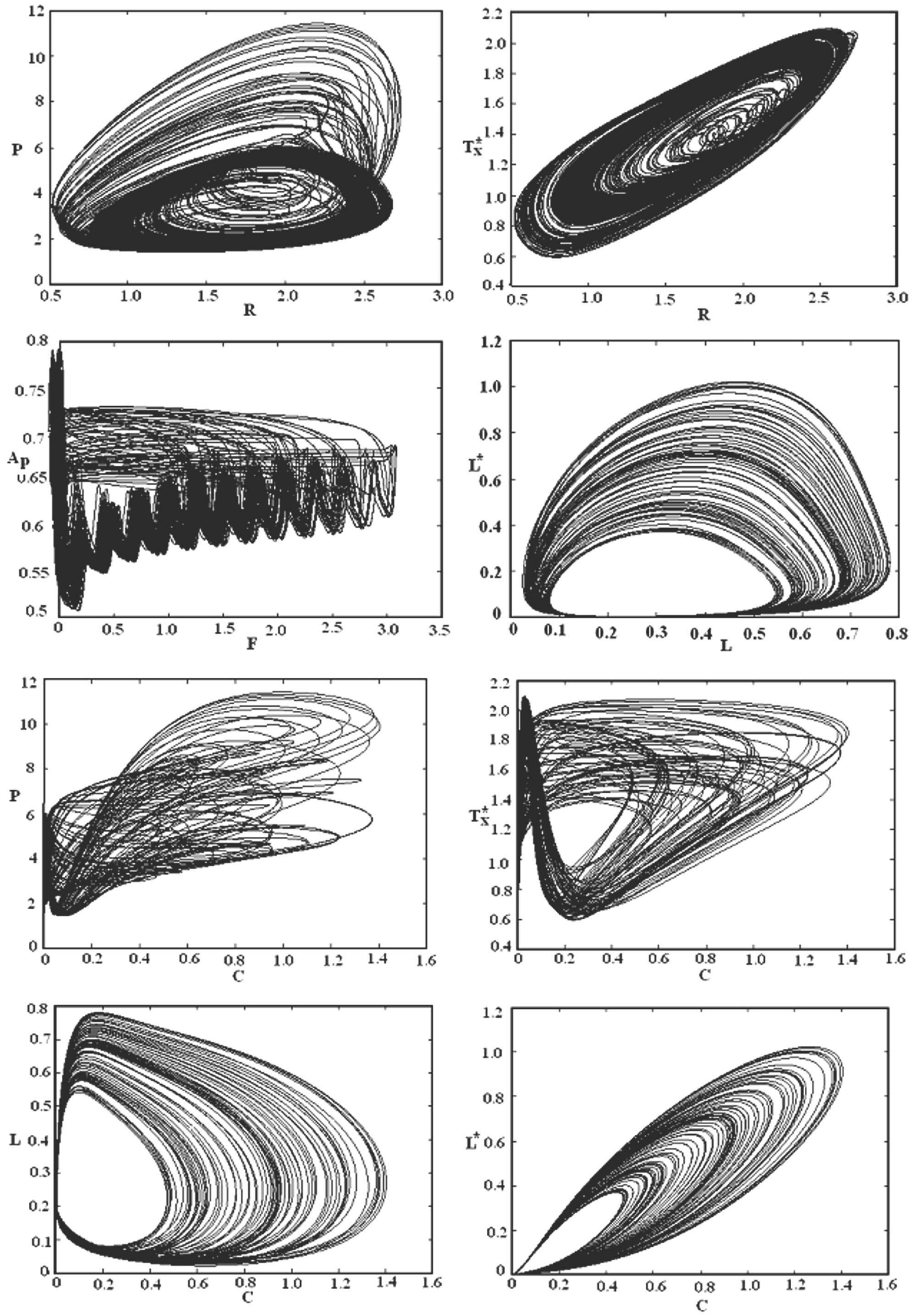

Fig. 5. Projections of the phase portrait of a strange attractor $1 \times 2^{x}$ at $\mu_{0}=0.437$ : in the plane $(R$, $P)(a)$; in the plane $\left(R, T_{x}^{*}\right)(b)$; in the plane $(C, P)(c)$; in the plane $\left(L, L^{*}\right)(d)$; in the plane $\left(P, T_{x}^{*}\right)$ $(e)$; in the plane $\left(C, T_{x}^{*}\right)(f)$; in the plane $(C, L)(g)$; in the plane $\left(C, L^{*}\right)(h)$ 

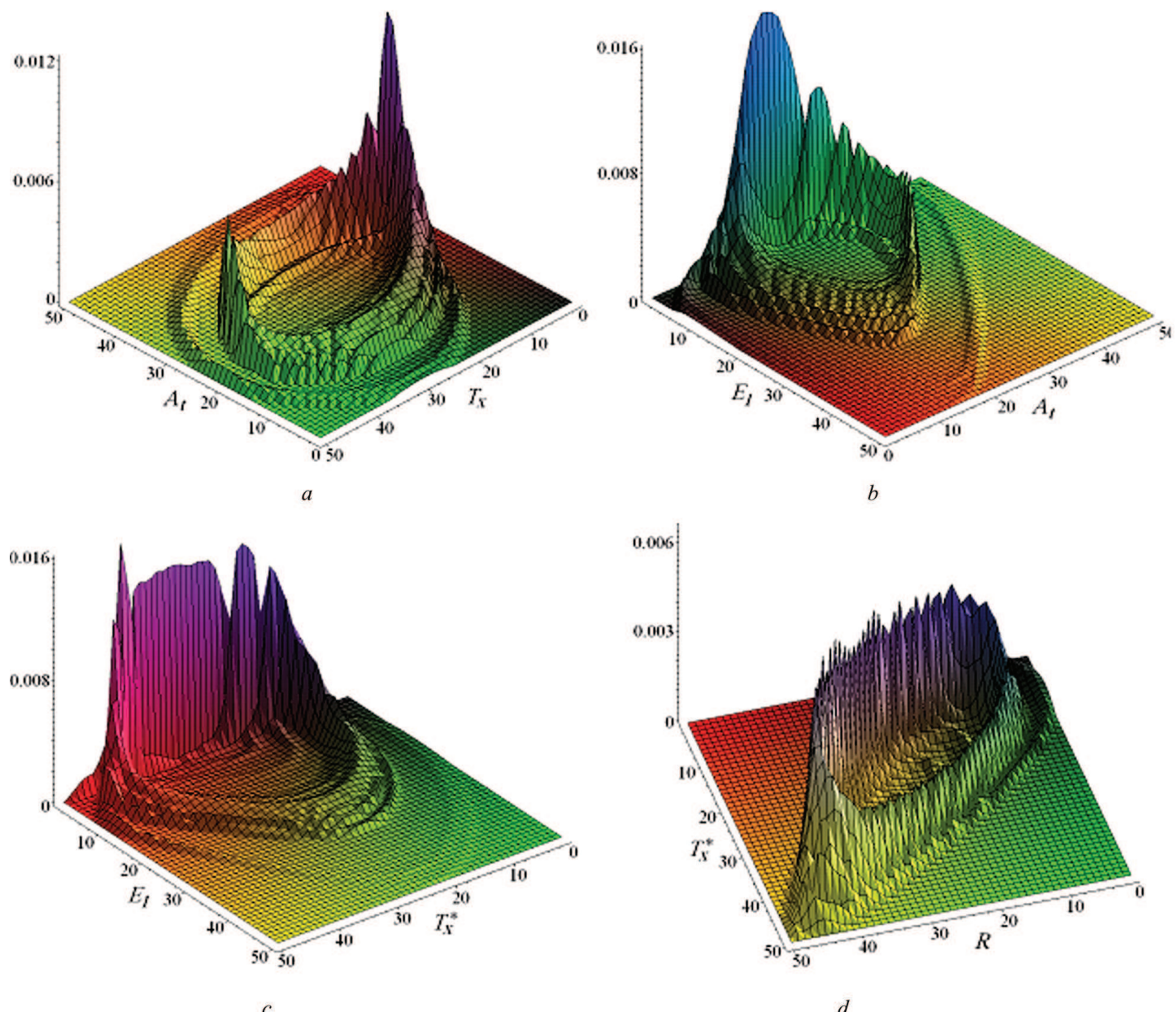

Fig. 6. Histograms of projections of the invariant measure of the strange attractor $1 \times 2^{x}, \mu_{0}=0.437$ : on the plane $\left(A_{t}, T_{x}\right)(a)$; on the plane $\left(E_{1}, A_{t}\right)(b)$; on the plane $\left(E_{1}, T_{x}^{*}\right)(c)$; on the plane $\left(R, T_{x}^{*}\right)(d)$

Fourier trigonometric series in the modes of successive period doubling. The plots of this curve on the corresponding time interval are shown in the upper right corners. In the construction of the spectral patterns, we took 1000 harmonics.

As the coefficient $\mu_{0}$ increases, the multiplicity of the autoperiodic process grows as well. According to the doubling of the multiplicity of the autoperiodic process, the number of basic peaks of harmonics increases two times (Fig. 3, $a, b, c$.), and, eventually, the harmonics of turbulence appear (Fig. 3,d). The given chaotic mode of the strange attractor $1 \times 2^{x}$ arises by the Feigenbaum scenario due to the intermittence at $\mu_{0}=0.437$ [22].

In Figs. 4 and 5, we present various projections of the mode of a strange attractor at $\mu_{0}=0.437$. It is ISSN 2071-0194. Ukr. J. Phys. 2021. Vol. 66, No. 3 seen that the given strange attractor is formed due to the funnel. There, we observe the mixing of trajectories which approach one another along some directions, but diverge along other ones. At a slight fluctuation due to the intermittence, the periodic process becomes unstable, and a determinate chaos arises.

Then we calculated the invariant measure of the obtained strange attractor. According to the KrylovBogolyubov theorem, at least one invariant measure exists in the case of a continuous mapping of the compact phase space of a dynamical system. Based on the calculated invariant measure of a strange attractor, we calculated and drew the histograms of projections of this measure on the corresponding planes (see Fig. 6). These histograms correspond to projections of the phase portrait (Figs. 4 and 5) and demonstrate 
clearly the course of a trajectory of the dynamical system in the phase space.

\section{Conclusions}

With the help of an improved mathematical model, we have studied the effect of "poor cholesterol" on the metabolic process of hemostasis of a blood vessel.

For the first time, the mechanism of influence of cytokines on the formation of atherosclerotic plaques of a vessel is modeled. Using the model, it is theoretically proven that this leads to the autocatalysis of a growth of atherosclerotic plaques and to the progressive development of atherosclerosis.

The thrombosis and antithrombosis systems are considered as dissipative ones. Their stationary dissipative structure defines the hemostasis of a blood vessel. The presence of "poor" cholesterol and cytokines disbalances the metabolic process, since they are autocatalysts and cause the formation of selfoscillating modes in hemostasis. Spectral analysis revealed a scenario of bifurcations with the doubling of the period of self-oscillations and a discontinuity in the formation of the mixing funnel chaotic modes of strange attractors. Various projections of the phase portrait of the strange attractor and histograms of projections of its invariant measure are constructed. The obtained results allow one to investigate the influence of low-density lipoproteins on the self-organization of the metabolic process of hemostasis of a blood vessel. It has been shown that cytokines formed in atherosclerotic plaques can cause thrombosis at any time anywhere in a blood vessel.

The present work was partially supported by the Program of Fundamental Research of the Department of Physics and Astronomy of the National Academy of Sciences of Ukraine "Mathematical models of non-equilibrium processes in open systems" No.0120U10085\%.

1. Great Medicinal Encyclopedia (Sovetsk. Entsikl., 1977), vol. 5, p. 223 (in Russian).

2. V.V. Verkhusha, V.M. Staroverov, P.V. Vrzhesh. The model of adhesive interaction of cells in the flow of a fluid. Biol. Membr. 11, No. 4, 437 (1994).

3. V.P. Baluda, M.V. Baluda, I.I. Deyanov. Physiology of the System of Hemostasis (Meditsina, 1995) (in Russian).

4. A.S. Shitikova. Thrombocytic Hemostasis (SPbSMU, 2000) (in Russian).
5. S.D. Varfolomeev, A.T. Mevkh. Prostaglandins - Molecular Bioregulators (Moscow University, 1985) (in Russian).

6. S.D. Varfolomeev, A.T. Mevkh, V.P. Gachok. Kinetic model of multienzyme system of blood prostanoid synthesis. 1. Mechanism of stabilization of the levels of thromboxane and prostacyclin. Molek. Biol. 20, No. 4, 957 (1986).

7. S.D. Varfolomeev, V.P. Gachok, A.T. Mevkh. Kinetic behavior of the multienzyme system of blood prostanoid synthesis. BioSystems. 19, 45 (1986).

8. P. Libby. The molecular bases of acute coronary syndromes. Circulation 91, No. 11, 2844 (1995).

9. M.J. Davies. Stability and Instability: The two faces of coronary atherosclerosis. Paul Dudley White Lecture 1995. Circulation 94, No. 8, 2013 (1996).

10. J. Berliner et al. Oxidized lipids in atherogenesis: Formation, destruction and action. Thrombosis and Haemostasis 78, No. 1, 195 (1997).

11. D. Steinberg. Low density lipoprotein oxidation and its pathobiological significance. J. Biolog. Chem. 272, No. 34, 20963 (1997).

12. P. Libby. Current concepts of the pathogenesis of the acute coronary syndroms. Circulation 104, No. 3, 365 (2001).

13. P. Libby. The vascular biology of atherosclerosis. In: Heart Disease: A Textbook of Cardiovascular Medicine. Edited by E. Braunwald, D.P. Zipes, P. Libby (Saunders, 2001) [ISBN: 0721685617, 9780721685618].

14. P. Libby, P.M. Ridker, A. Maseri. Inflammation and atherosclerosis. Circulation 105, No. 9, 1135 (2002).

15. P. Libby. Atherosclerosis: New look. Svit Nauky Nos. $4-5$ (15-16), 19 (2002).

16. V.I. Grytsay, V.P. Gachok. Self-organization in fusion system of tromboxan and Prostacyclin. In: Abstracts of the $V$ International Congress on Mathematical Modelling, $V$ ICMM, September 30-October 6, 2002, Dubna, Moscow Region, Vol. II, p. 200.

17. V.I. Grytsay. Conditions of self-organization of the multienzyme prostacyclin-thromboxane system. Bulletin of the Univ. of Kiev. Ser. Phys. \&5 Math. No. 3, 372 (2002).

18. V.I. Grytsay, V.P. Gachok. Regimes of self-organization in system of prostacyclin and tromboxan. Bulletin of the Univ. of Kiev. Ser. Phys. \& Math. No. 4, 365 (2002).

19. V.I. Grytsay. Processes Modeling of the multienzyme prostacyclin and thromboxan system. Bulletin of the Univ. of Kiev. Ser. Phys. \&3 Math., No. 4, 379 (2003).

20. V.I. Grytsay, V.P. Gachok. Ordered structures in mathematical system of prostacyclin and tromboxan model. Bulletin of the Univ. of Kiev. Ser. Phys. \& Math. No. 1, 338 (2003).

21. V.I. Grytsay. Processes modelling of the multienzyme prostacyclin and tromboxan system. Bulletin of the Univ. of Kiev. Ser. Phys. \& Math. No. 4, 379 (2003).

ISSN 2071-0194. Ukr. J. Phys. 2021. Vol. 66, No. 3 
22. V.I. Grytsay. Self-organization and chaos in the metabolism of hemostasis in a blood vessel. Ukr. J. Phys. 61, No. 7, 648 (2016).

23. V.I. Grytsay. A mathematical model of the metabolic process of atherosclerosis. Ukr. Biochem. J. 88, No. 4, 75 (2016).

24. V.S. Anishchenko. Complex Oscillations in Simple Systems (Nauka, 1990) (in Russian).

25. S.P. Kuznetsov. Dynamical Chaos (Fizmatlit, 2001) (in Russian).

26. V.I. Grytsay. The self-organization in a macroporous structure of a gel with immobilized cells. The kinetic model of a bioselective membrane of biosensor. Dopov. NAN Ukr. No. 2, 175 (2000).

27. V.I. Grytsay. The self-organization in a reaction-diffusion porous medium. Dopov. NAN Ukr. No. 3, 201 (2000).

28. V.P. Gachok, V.I. Grytsay. The kinetic model of a macroporous granule with the regulation of biochemical proceses. Dokl. AN SSSR 282, No. 1, 51 (1985).

29. V.P. Gachok., V.I. Grytsay, A.Yu. Arinbasarova, A.G. Medentsev, K.A. Koshcheyenko, V.K. Akimenko. Kinetic model of hydrocortizone 1-en dehydrogenation by Arthrobacter globiformis. Biotechn. Bioengin. 33, 661 (1989).

30. V.P. Gachok, V.I. Grytsay, A.Yu. Arinbasarova, A.G. Medentsev, K.A. Koshcheyenko, V.K. Akimenko. Kinetic model for the regulation of redox reactions in steroid transformation by Arthrobacter globiformis cells. Biotechn. Bioengin. 33, 668 (1989).

31. V.I. Grytsay. Ordered structures in the mathematical model of a biosensor. Dopov. NAN Ukr. No. 11, 112 (2000).

32. V.I. Grytsay. The self-organization of the biochemical process of immobilized cells of a bioselective membrane of a biosensor. Ukr. Fiz. Zh. 46, No. 1, 124 (2001).

33. V.I. Grytsay. Ordered and chaotic structures in the reaction-diffusion medium. Visn. Kyiv. Univ. No. 2, 394 (2002).

34. V.I. Grytsay. Conditions of self-irganization of the prostacyclin-thromboxane system. Visn. Kyiv. Univ. No. 3, 372 (2002).

35. V.V. Andreev, V.I. Grytsay. Modeling of nonactive zones in porous granules of a catalyst and in a biosensor. Matem. Model. 17, No. 2, 57 (2005).

36. V.V. Andreev, V.I. Grytsay. Influence of the inhomogeneity of running of a diffusion-reaction process on the formation of structures in the porous medium. Matem. Modelir. 17, No. 6, 3 (2005).

37. V.I. Grytsay, V.V. Andreev. The role of diffusion in the formation of nonactive zones in porous reaction-diffusion media. Matem. Modelir. 18, No. 12, 88 (2006).

38. V.I. Grytsay. Unsteady conditions in porous reactiondiffusion medium. Romanian J. Biophys. 17, No. 1, 55 (2007).

39. V.I. Grytsay. Uncertainty of the evolution of structures in the reaction-diffusion medium of a bioreactor. Biofiz. Visn. Iss. 2 (19), 92 (2007).
40. V.I. Grytsay. Formation and stability of the morphogenetic field of immobilized cells of a bioreactor. Biofiz. Visn., Iss. 1 (20), 48 (2008).

41. V.I. Grytsay. Prediction structural instability and type attractor of biochemical process. Biofiz. Visn. Iss. 23 (2), 77 (2009).

42. V.I. Grytsay. Structural instability of a biochemical process. Ukr. J. Phys. 55 (5), 599 (2010).

43. V.I. Grytsay, I.V. Musatenko. The structure of a chaos of strange attractors within a mathematical model of the metabolism of a cell. Ukr. J. Phys. 58, No. 7, 677 (2013).

44. V.I. Grytsay, I.V. Musatenko. Self-oscillatory dynamics of the metabolic process in a cell. Ukr. Biochim. Zh. 85, No. 2, 93 (2013).

45. V.I. Grytsay, I.V. Musatenko. A mathematical model of the metabolism of a cell. CMSIM 2, No. 4, 539 (2013).

46. V.I. Grytsay, I.V. Musatenko. Self-organization and fractality in a metabolic processes of the Krebs cycle. $U k r$. Biokhim. Zh. 85, No. 5, 191 (2013).

47. V.I. Grytsay, I.V. Musatenko. Self-organization and chaos in the metabolism of a cell, Biopolymers and Cells, 30, No. 5, 404 (2014).

48. V. Grytsay, I. Musatenko. Nonlinear self-organization dynamics of a metabolic process of the Krebs cycle. CMSIM 3, 207 (2014).

49. V. Grytsay. Lyapunov indices and the Poincaré mapping in a study of the stability of the Krebs cycle. Ukr. J. Phys. 60, No. 6, 564 (2015).

50. V.I. Grytsay. Self-organization and fractality in the metabolic process of glycolysis. Ukr. J. Phys. 60, No. 12, 1253 (2015).

51. V.I. Grytsay. Self-organization and fractality created by gluconeogenesis in the metabolic process. CMSIM 5, 113 (2016).

52. V.I. Grytsay. Spectral analysis and invariant measure in the study of a nonlinear dynamics of the metabolic process in cells. Ukr. J. Phys. 62, No. 5, 448 (2017).

53. V.P. Gachok. Kinetics of Biochemical Processes (Naukova Dumka, 1988) (in Russian).

54. V.P. Gachok. Strange Attractors in Biosystems (Naukova Dumka, 1989) (in Russian).

55. G.Yu. Riznichenko. Mathematical Models in Biophysics and Ecology (Inst. of Computer. Studies, Moscow, Izhevsk, 2003) (in Russian).

56. Yu.M. Romanovskii, N.V. Stepanova, D.S. Chernavskii. Mathematical Biophysics (Nauka, 1984) (in Russian).

57. E.E. Selkov. Self-oscillations in glycolysis. Europ. J. Biochem. 4, 79 (1968).

58. O.P. Matyshevska, A. Yu. Karlash, Ya. V. Shtogum, A. Benilov, Yu. Kirgizov, K. O. Gorchinskyy, E.V. Buzaneva, Yu. I. Prylutskyy, P. Scharff. Self-organizing DNA/carbon nanotube molecular films. Mater. Sci. Engin. C 15, Nos. 1-2, 249 (2001). 
59. S.V. Prylutska, O.P. Matyshevska, I.I. Grynyuk, Yu.I. Prylutskyy, U. Ritter, P. Scharff. Biological effects of $\mathrm{C}_{60}$ fullerenes in vitro and in a model system. Mol. Cryst. Liq. Cryst. 468, 265-274 (2007).

Received 24.08.20

B.I. Грицай

СПЕКТРАЛЬНИЙ АНАЛІЗ

ТА IHВАРІАНТНА МІРА ПРИ ВИВЧЕННІ

ДИНАМІКИ ГЕМОСТАЗУ КРОВОНОСНОЇ СУДИНИ

В даній роботі продовжується дослідження математичної моделі атеросклерозу кровоносної судини з урахуван- ням надходження в кров ліпопротеїдів низької щільності (ЛПНЩ). В даній моделі вперше враховано вплив цитокінів на запалення судини при утворенні атеросклеротичних бляшок. За допомогою розкладу в ряд Фур'є та розрахунку інваріантної міри досліджено сценарій виникнення дивних атракторів у залежності від зміни параметра дисипації холестерина. Зроблено висновки про взаємозв'язок між динамікою метаболічного процесу кровоносної системи і її фізичним станом.

Ключові слова: гемостаз, самоорганізація, дивний атрактор, ряд Фур'є, інваріантна міра, ЛПНЩ, цитокіни. 